\title{
Rohingya Crisis in Bangladesh and Health Sector Challenges
}

\author{
MT Rahman
}

\section{Introduction}

The term Rohingya is used to distinguish an ethnic, linguistic and religious group who lived in the former Arakan State of Myanmar. This people are officially stateless and disowned by the Myanmar government with the argument that they are not Myanmar citizens and originally came from Bangladesh. ${ }^{1}$ Forced migration of Rohingya refugees were first seen in 1978 and again in 1991$1992 .{ }^{2}$ Almost 250,000 people migrated to Bangladesh during these two periods. ${ }^{3}$ The government of Bangladesh received Rohingya refugees with great deal of sympathy and provided all form of support including relief, temporary shelter, food, medical care including health and sanitation affairs during first influx in 1978. However, it is decided that the refugees could not stay for a longer period and had to return Myanmar as soon as possible. In this context, government of Bangladesh attempted a large scale repatriation based on Bangladesh Myanmar Memorandum of Understanding (MOU) in response to this refugee flow. As a result, the first repatriation began on a very limited scale on 22 September, $1992 .{ }^{4}$ But, this was not voluntary. Most of those who fled to Bangladesh did not get official status as refugees from Bangladesh government. ${ }^{5}$ Currently, only 32,000 Rohingyas have been recognized as refugees and are living in two camps, while 35,000 unrecognized refugees have taken shelter in makeshift sites. In addition, an estimated 300,000 undocumented Rohingyas are living in the host communities. ${ }^{6}$ In refugee's camps, more than 50\% are children; aged younger than 18 years and most visible and vulnerable population in the camps due to lack of health care system, personal hygiene, shelter, sanitation and violence. In general the health status of refugees in various countries is reported to be poor with malnutrition being the major health problem due to lack of access to sufficient food and nutrition intakes. Other problem includes mental illness, intestinal parasites, hepatitis B, tuberculosis, sexually transmitted diseases, HIV/AIDS, malaria and anemia. 7,8 In refugee camps, medical services are mostly crippled as there is no examination and with the exception of some community health centers (RHU), there is no pregnant women and infant monitoring either, since family planning services for refugees are not available, there are unwanted births and increase in infant mortality, women additionally face risk of gender discrimination, sexual violence, early marriage and miscarriage and birth complications. ${ }^{9}$

\section{Existing Situation}

It is estimated that 618,000 Rohingyas from Myanmar have arrived in Cox's Bazar, Bangladesh since 25 August 2017 of which 1.2 million people are in need of health assistance. At least 65 national and international health sector partners are in operation. Since $25^{\text {th }}$ August 653755 health care service consultations delivered, 712797 people aged one year and Above given oral cholera vaccine, 199 472 children aged one to five years vaccinated with second dose of oral cholera vaccine. ${ }^{10}$

\section{Challenges}

World Health Organization (WHO) has graded this crisis as a level 3 emergency based on the public health situation analysis published on 10th October 2017. The ongoing challenges and needs faced by the health sector includes: (a). Overburden government health care facilities at (Sadar Hospital in Cox's Bazar and Teknaf and Ukhia upazila health complexes \& PHC) (b). Severe Acute Malnutrition at $7.5 \%$ as well over the emergency threshold level (c). Inequitable access to services due to new arrivals.(d). Communicable disease risks due to crowded living conditions, inadequate water and

Prof. Dr. Md. Tahminur Rahman, Visiting Professor, Department of Pathology, AKMMC

*Corresponding Author

AKMMC J 2018; 9(1) : 03-04 
sanitation facilities and low vaccination coverage. As of 11 November 2017, 611 suspected cases of measles were reported. (e). Seasonal threats as cyclone in Cox's Bazar, the incidence of acute respiratory infections (ARI), topography of the camps having the risk of landslides in the next rainy seasons. (f). Sexual and reproductive health demands maternal, child and newborn health services, particularly obstetric services that are inadequate in hard to reach areas. (g). Mental and psychological health needs are immense due to physical \& mental trauma as a result of violence, including sexual and gender-based violence (SGBV) as well.10 Currently, Rohingya crisis demands urgent implementation of a multi-sectoral humanitarian response plan that published in early October 2017. This plan focus on three strategic objectives: 1. Providing life saving basic assistance in settlements, camps and host communities. 2 . Improving conditions and management of both existing and new settlements, including infrastructure and site planning and 3. Promote safety, dignity and respect for individual rights of the affected population. ${ }^{10}$

\section{Conclusion}

In addition health sector response planning to meet all those challenges, there are other challenges like; health sector funding, health sector coordination, health sector response to service delivery planning, disease surveillance as well as challenges to health and WASH, Vaccines and immunization, nutrition, sexual and reproductive health including mental and psychological health are also the big challenges in deed. The challenges for contingency planning should also be addressed for any epidemic and natural disaster situation in particular.

\section{References}

1. Médecins Sans Frontières (MSF). (2010, February 18) Bangladesh: Violent crackdown fuels humanitarian crisis for unrecognized Rohingya refugees. Retrieved from http:// www. doctorswithoutborders.org/news-stories/ special-report/ bangladesh-violent-crackdownfuels-humanitarian-crisis-unrecognized
2 . Smith, M. (1995, December). The Muslim Rohingya of Burma. Paper presented at the Conference of Burma Centrum Nederland.

3. Imran, H. F. A. \& Mian, M. N. (2014). The Rohingya refugees in Bangladesh: A vulnerable group in law and policy. Journal of Studies in Social Sciences 8(2): 226-253.

4. Abrar, C.R. (1994). Repatriation of Rohingya refugees. Retrieved from http:// www. burmalibrary. org/docs/Abrar-repatriation.htm

5. Feeny, T. (2001). Rohingya refugee children in Cox's Bazar, Bangladesh. A discussion document prepared for UNICEF Regional Office South Asia. Dhaka: UNICEF.

6. Zinnat, M. A. (2016, 18 June). 3 lakh Rohingyas staying illegally. The Daily Star. Retrieved from http://www.thedailystar.net/ frontpage/three-lakh-illegal-rohingyas-1241512

7. Teng TS, Zalilah MS. Nutritional status of rohingya children in kuala lumpur. Malaysian $\mathbf{J}$ Med Heal Sci. 2011; 7(1): 41-9.

8. Kemmer TM, Bovill ME, Kongsomboon W, Hansch SJ, Geisler KL, Cheney C, et al. Iron deficiency is unacceptably high in refugee children from Burma. J Nutr. 2003; 133(12): 4143-9

9. Sharara SL, Kanj SS. War and infectious diseases: challenges of the Syrian civil war. PLoS Pathog. 2014; 10(10): e1004438.

10. https:// reliefweb.int/ report/ bangladesh/ bangladesh-humanitarian-response-planseptember-2017-february-2018-rohingya 1 https:// reliefweb.int/ report/ bangladesh/ bangladesh-humanitarian-response-planseptember-2017-february-2018- rohingya 